\title{
Analysis of Genetic Variability Amongst Polyploid Genotypes of Pteris vittata L. From Various Geographic Locales of India
}

\author{
Jyoti Mathur ${ }^{1 *}$, P. B. Khare ${ }^{2}$, Apurva Panwar ${ }^{1}$ and S. A. Ranade ${ }^{2 \dagger}$ \\ ${ }^{1}$ Bioscience \& Biotechnology Department, Banasthali Vidyapith, Tonk, India, ${ }^{2}$ National Botanical Research Institute (CSIR), \\ Lucknow, India
}

OPEN ACCESS

Edited by:

Sangeeta Saxena,

Babasaheb Bhimrao Ambedkar

University, India

Reviewed by:

Jinming Chen,

Wuhan Botanical Garden, Chinese

Academy of Sciences, China

Devindra Amla,

National Botanical Research Institute

(CSIR), India

Yong-He Han,

Fujian Normal University, China

Heena Ambreen,

National Institute of Plant Genome

Research (NIPGR), India

*Correspondence:

Jyoti Mathur

contact.srivastava@gmail.com

orcid.org/0000-0001-7084-7643

${ }^{\dagger}$ Deceased

Specialty section:

This article was submitted to Evolutionary and Population Genetics, a section of the journal

Frontiers in Ecology and Evolution

Received: 04 October 2020

Accepted: 06 August 2021

Published: 14 September 2021

Citation:

Mathur J, Khare PB, Panwar A and Ranade SA (2021) Analysis

of Genetic Variability Amongst Polyploid Genotypes of Pteris vittata L. From Various Geographic Locales of India. Front. Ecol. Evol. 9:613847.

doi: 10.3389/fevo.2021.613847
Pteris vittata $L$. is very common and a widely distributed species belongs to the family Pteridaceae. Various cytotypes from diploid to octaploid is available in this fern species. The present work has been carried out for genetic diversity in this fern both within and between the cytotypes. The molecular analysis at inter- as well as intra-species has been carried out with 57 accessions of $P$. vittata as well as of other species of Pteris with Microsorium punctatum considered as an out group taxon. For the present study 48 P. vittata (36 tetraploid and 12 pentaploid) and five of other species (four P. cretica, one P. pellucida, one P. tremula, one P. quadriaurita, and two P. ensiformis) accessions were used. The UPGMA (unweighted pair group method with arithmetic mean) dendrograms were generated for each method separately, as well as for all methods cumulatively, after a 1000 replicate bootstrap analysis. In order to determine the utility of each of the method, a comparative statistical assessment was done and marker index (MI), expected average heterozygosity, fraction of polymorphic loci and effective multiplex ratio (EMR) were calculated in case of each of the methods used in the present study. At the level of individual methods highest $\mathrm{Ml}$ was obtained for directed amplification of minisatellites DNA (DAMD) method. Our findings of the present study concluded that out of the three methods Random Amplified Polymorphic DNA (RAPD), Inter-Simple Sequence Repeat (ISSR), and Directed Amplification of Minisatellite DNA (DAMD), DAMD was the best in term of polymorphism and heterozygosity as scores exhibited highest MI. The different accessions of $P$. vittata collected from different phytogeographical regions falls into six groups. Out of six clusters, one cluster is of pentaploid cytotype, four clusters are of tetraploid cytotype and one for outgroup taxon ( $M$. punctatum). The result thus showed that within tetraploid, heterozygosity with variable genomic structure exists.

Keywords: Pteris vittata, polyploid, ISSR, DAMD, RAPD, genetic diversity

\section{INTRODUCTION}

The pteridophytes are amongst the oldest existing land plants and include the largest proportion of polyploid species (Ramsey and Schemske, 1998; Soltis and Soltis, 2000; Leitch and Bennett, 2004). Polyploidy have been considered as one of the factors for long survival of the ferns as well as for their global distribution from more than 360 million years ago till date. Polyploidy helps the pteridophytes in overcoming not only the negative effects of inbreeding due to isolation 
of populations but also the buffering effects for variations and this in turn helps in successful colonisation by the plants (Soltis et al., 2004; Otto and Sauquet, 2018). The pteridophytes include ferns and fern allies of which the ferns are the dominant group extant today. Amongst the common ferns, Pteris L. is an almost exclusively tropical fern genus with 330 species and 3 hybrids (Hassler and Swale, 2001). The genus includes terrestrial and perennial species that grow well in both xeric and moist shady habitats. In India, about 45 species of Pteris have been reported; however, there are no reports of any comprehensive survey and analysis of their diversity and biosystematics of the genus (Aulakh et al., 2019). The Brake Fern or Pteris vittata L. is very common and a widely distributed species occurring at higher altitudes up to $1600 \mathrm{~m}$ also. This fern is actually a "species complex" in India and includes five cytotypes viz. diploid, triploid, tetraploid, pentaploid, and hexaploid (Khare and Kaur, 1983a) with the basic number being 29 chromosomes. Other such species complexes with multiple ploidy levels such as Adiantum raddianum Presl. with a range of ploidy from diploid to octoploid and Diplazium subsinuatum (Wall.) Tagawa with tetra-, penta-, and hexaploid cytotypes are also known (Bir and Irudayaraj, 2001; Kuo et al., 2018).

Polyploidisation has apparently played an important role in the distribution of $P$. vittata and other cytotypes have also been reported in India. All the cytotypes, however, do not occur in all the regions. A study of the distribution status and occurrence of the different cytotypes suggested that some of them may have become scarce if not altogether extinct in the country (Srivastava et al., 2007). The successful colonisation of the $P$. vittata cytotypes over a wide distribution range (from Himalayas to South India) indicates the existence of wide adaptability of the genus with genetic variability. Studies on spore germination, gametophyte differentiation and reproductive biology of the different polyploid cytotypes of $P$. vittata have been carried out by Khare and Kaur (1992) and Khare (1995). However, not much work has been reported on the genetic diversity in this fern both within and between the cytotypes. We have earlier reported the Random amplified polymorphic DNA (RAPD) profile differences among 23 accessions of $P$. vittata and have observed average 52\% similarity (range 0.12-0.82 similarity coefficients) amongst the accessions based on the profiles generated with 11 RAPD primers (Srivastava et al., 2008). A few other reports are available about the use of molecular markers including nuclear gapCp markers (Schuettpelz et al., 2008) and minisatellites (Yang et al., 2010) for determining polymorphism in case of Pteridophyte DNA profiles. In other studies, Schuettpelz et al. (2007) have determined the molecular phylogeny of the Pteridaceae family while recently Chao et al. (2012) have investigated polyploidy and speciation in Pteridaceae, albeit at the cytological levels. The Single Primer Amplification Reaction (SPAR) methods including Inter-Simple Sequence Repeat (ISSR), Directed Amplification of Minisatellite DNA (DAMD) and Random Amplified Polymorphic DNA (RAPD), are powerful methods capable of even individual-specific resolution and are routinely used in our laboratory to determine genetic variation at both intra- as well as inter-species level in several flowering plants including mango (Srivastava et al., 2007); mungbean
(Lavanya et al., 2008); pomegranates (Ranade et al., 2009; Narzary et al., 2010); Jatropha curcas (Ranade et al., 2008); species of Sapindus and Murraya (Verma et al., 2009; Mahar et al., 2011, Mahar et al., 2012) to name a few and pteridophytes $P$. vittata and Equisetum species (Srivastava et al., 2008, 2009). The SPAR methods have been used in case other polyploidy plants to resolve genetic diversity (Fjellheim et al., 2001; Bhattacharya et al., 2005; Peirson et al., 2013). In this paper we report on the genetic diversity among several tetraploid and pentaploid accessions of $P$. vittata collected from different places in India using three different SPAR methods that cumulatively reveal genetic diversity amongst the $P$. vittata accessions independent of their geographical habitat as well as their ploidy levels. P. vittata is species complex and with the help of molecular studies the genome analysis of the gene pool of different ploidy and their correlation within may be assessed and evolutionary status can be assessed. The study will reveal the clear-cut evolution of genotypes of different ploidy can so that the taxonomic confusions may be addressed with the help of present analysis.

\section{MATERIALS AND METHODS}

\section{Plants}

A number of plants were collected from different locations in India (Figure 1) and of these only tetraploid and pentaploid accessions were selected (Table 1) for the present study since multiple accessions for each cytotype were available. It is pertinent to note here that the pentaploid plants are maintained in NBRI fernery for more than two decades and their exact provenance in the wild is not known. Young fronds were harvested from the plants, washed free of dust, mopped dry and quickly frozen and powdered in liquid nitrogen. The powders were either used for isolation of DNA immediately, or were stored in a deep freezer $\left(-80^{\circ} \mathrm{C}\right)$ for long-term storage.

\section{Determination of Ploidy Level}

For chromosome analysis young sporophylls, harvested at the time that the tissue was collected for DNA isolation, were fixed in 3:1 (v/v) absolute alcohol and acetic acid (Carnoy's fixative) for at least $24 \mathrm{~h}$, following which these were squashed in $2 \%$ $(\mathrm{w} / \mathrm{v})$ acetocarmine solution for determining the numbers of chromosomes, according to method of Manton (1950).

\section{Isolation of DNA}

Total genomic DNA was isolated from the powdered and frozen tissue using Cetyl Trimethyl Ammonium Bromide (CTAB) detergent according to the procedure of Rogstad (1993) with minor modifications. At least three independent DNA preparations were made from tissues collected from each accession. The quantity and quality of DNA samples were estimated by agarose gel method (Sambrook et al., 1989).

\section{Polymerase Chain Reaction Using SPAR Primers}

The different SPAR primers used in the present study are listed in Table 2. The tabulated lists of primers are those selected after 




FIGURE 1 | Map of India showing different locations of collected Pteris accessions.

such preliminary pilot studies. DNA was amplified essentially following Gupta et al. (1994) in the ISSR method, Zhou et al. (1997) in the DAMD method and Williams et al. (1990) in the RAPD method. The entire sets of DNAs were tested with the selected primers to generate profiles for this study. The optimised ISSR reaction conditions included $50 \mathrm{ng}$ template DNA, 10 pmoles primer, $0.2 \mathrm{mM}$ each dNTP, 1.5 Units of Taq DNA polymerase in suitable reaction buffer (both enzyme and buffer were procured from Bangalore Genei, Bangalore, India) with $2.0 \mathrm{mM}$ magnesium ion concentration in a total reaction volume of $25 \mu \mathrm{l}$. The thermal cycler was programmed to allow pre-denaturation for $180 \mathrm{~s}$ at $94^{\circ} \mathrm{C}$ followed by 45 cycles of denaturation for $45 \mathrm{~s}$ at $94^{\circ} \mathrm{C}$, annealing for $45 \mathrm{~s}$ at $50^{\circ} \mathrm{C}$, extension for $60 \mathrm{~s}$ at $72^{\circ} \mathrm{C}$. The final cycle allowed additional extension for $300 \mathrm{~s}$ at $72^{\circ} \mathrm{C}$. In case of the DAMD reaction conditions were same as for ISSR except that the 20 pmoles primer and $2.5 \mathrm{mM}$ magnesium ion concentration was used in each reaction. The thermal cycler was programmed to allow pre-denaturation for $60 \mathrm{~s}$ at $94^{\circ} \mathrm{C}$ followed by 40 cycles of denaturation for $60 \mathrm{~s}$ at $94^{\circ} \mathrm{C}$, annealing for $120 \mathrm{~s}$ at $55^{\circ} \mathrm{C}$, extension for $120 \mathrm{~s}$ at $72^{\circ} \mathrm{C}$. The final cycle allowed additional extension for $300 \mathrm{~s}$ at $72^{\circ} \mathrm{C}$. In case of RAPD reaction conditions were the same as for DAMD except that the thermal cycler was programmed to allow pre-denaturation for $180 \mathrm{~s}$ at $94^{\circ} \mathrm{C}$ followed by 45 cycles of denaturation for $45 \mathrm{~s}$ at $94^{\circ} \mathrm{C}$, annealing for $45 \mathrm{~s}$ at $35^{\circ} \mathrm{C}$, extension for $60 \mathrm{~s}$ at $72^{\circ} \mathrm{C}$. The final cycle allowed additional extension for $300 \mathrm{~s}$ at $72^{\circ} \mathrm{C}$.

\section{Agarose Gel Electrophoresis}

Amplification products were separated by gel electrophoresis (at a constant current of $50 \mathrm{~mA}$ ) through $1.5 \%$ agarose gels in 0.5x TBE buffer, with DNA size standard (Low range DNA ruler, Bangalore Genei, Bangalore, India). After staining in ethidium bromide the gels were visualised and imaged using gel documentation system (Vilber Lourmat, France).

\section{Data Analysis}

Data (fragment sizes of all the amplification products, estimated from the gel by comparison with standard molecular weight marker) were scored as discrete variables, using "1" to indicate presence and "0" to indicate absence of a band. From the band data, monomorphic and polymorphic bands were identified. A pair wise matrix of similarity between genotypes was determined for the band data using Jaccard's similarity coefficient (Jaccard, 1908) for UPGMA method in the Free Tree programme (ver. 0.9.1.5; Pavlicek et al., 1999) for each SPAR method individually. In order to determine the utility and relative efficiency of each SPAR methods used, the similarity indices were averaged for the comparison between $P$. vittata and other Pteris species by all three methods. The polymorphic fraction, average heterozygosity of polymorphic bands, EMR and MI were calculated according to Powell et al. (1996) and Belaj et al. (2003). Expected heterozygosity $\mathbf{H}_{n}$ for genetic markers was calculated from the sum of the squares of the allele frequency using the 
TABLE 1 | Pteris vittata and other Pteris species included for the studies on PCR-based profiling analysis are given below.

\begin{tabular}{|c|c|c|c|c|}
\hline $\begin{array}{l}\text { Sample } \\
\text { number }\end{array}$ & Taxon & $\begin{array}{l}\text { Voucher } \\
\text { number }\end{array}$ & Locale/Habitat & Cytotype \\
\hline PV1 & $\begin{array}{c}\text { Pteris } \\
\text { vittata } \mathrm{L} \text {. }\end{array}$ & 229832 & FH, NBRI, UP Lucknow, UP & $5 x$ \\
\hline PV2 & -do- & 229833 & FH, NBRI, UP & $5 x$ \\
\hline PV3 & -do- & 222581 & Gurana, Pithoragarh, UKD & $4 x$ \\
\hline PV4 & -do- & 229835 & $\mathrm{FH}, \mathrm{NBRI}, \mathrm{UP}$ & $4 x$ \\
\hline PV5 & -do- & 229836 & $\mathrm{FH}, \mathrm{NBRI}, \mathrm{UP}$ & $4 x$ \\
\hline PV6 & -do- & 54252 & Kainchee Nainital UKD & $4 x$ \\
\hline PV7 & -do- & 229838 & FH, NBRI, UP & $4 x$ \\
\hline PV8 & -do- & 229839 & FH, NBRI, UP & $4 x$ \\
\hline PV9 & - do- & 229840 & FH, NBRI, UP & $4 x$ \\
\hline PV10 & -do- & 229841 & FH, NBRI, UP & $4 x$ \\
\hline PV11 & -do- & 229842 & Coimbatore, TN & $4 x$ \\
\hline PV12 & -do- & 229843 & Gorakhpur, UP & $4 x$ \\
\hline PV13 & -do- & 229844 & Kolkata, WB & $4 x$ \\
\hline PV14 & -do- & LP & FH, NBRI, UP & $4 x$ \\
\hline PV15 & -do- & 229845 & FH, NBRI, UP & $5 x$ \\
\hline PV16 & -do- & 229846 & FH, NBRI, UP & $5 x$ \\
\hline PV17 & -do- & 229847 & $\mathrm{FH}, \mathrm{NBRI}, \mathrm{UP}$ & $5 x$ \\
\hline PV18 & -do- & 229848 & FH, NBRI, UP & $5 x$ \\
\hline PV19 & -do- & 229849 & FH, NBRI, UP & $5 x$ \\
\hline PV20 & -do- & 229850 & FH, NBRI, UP & $5 x$ \\
\hline PV21 & -do- & 229851 & FH, NBRI, UP & $4 x$ \\
\hline PV22 & -do- & 229852 & FH, NBRI, UP & $5 x$ \\
\hline PV23 & -do- & 229853 & $\mathrm{FH}, \mathrm{NBRI}, \mathrm{UP}$ & $5 x$ \\
\hline PV24 & -do- & DNS & Calicut, KER & $4 x$ \\
\hline PV25 & -do- & DNS & RFRS Pune, MAH & $4 x$ \\
\hline PV26 & -do- & NA & Lonavala, MAH & $4 x$ \\
\hline PV27 & -do- & 223322 & $\begin{array}{l}\text { Komboikkode, Kodaikanal, } \\
\text { TN }\end{array}$ & $4 x$ \\
\hline PV28 & -do- & 223324 & Palayamkottai, Tirunelveli, TN & $4 x$ \\
\hline PV29 & -do- & NA & Palayamkottai, Tirunelveli, TN & $4 x$ \\
\hline PV30 & -do- & NA & NEHU, Shillong, MEG & $4 x$ \\
\hline PV31 & -do- & NA & Cherrapunji, MEG & $4 x$ \\
\hline PV32 & -do- & DNS & BSI Itanagar AP & $4 x$ \\
\hline PV33 & - do- & DNS & NEHU Shillong, MEG & $4 x$ \\
\hline PV34 & - do- & 229855 & Shilong Peak, MEG & $4 x$ \\
\hline PV35 & -do- & DNS & Cherapunji, MEG & $4 x$ \\
\hline PV36 & -do- & DNS & Andheri Falls, Gangtok, SKM & $4 x$ \\
\hline PV37 & -do- & 223337 & Tippajharia, Sonebhadra, UP & $4 x$ \\
\hline PV38 & -do- & NA & Renukoot, MP & $4 x$ \\
\hline PV 39 & -do- & 223331 & Shaktinagar, Sonebhadra, UP & $4 x$ \\
\hline PV40 & - do- & 223332 & Anpara, U.P. & $4 x$ \\
\hline PV41 & -do- & 223400 & $\begin{array}{l}\text { Shaktinagar (Jwalamukhi) } \\
\text { Sonebhadra, UP }\end{array}$ & $4 x$ \\
\hline PV42 & -do- & 223330 & $\begin{array}{l}\text { Karahiyanala, Sonebhadra, } \\
\text { UP }\end{array}$ & $4 x$ \\
\hline PV 43 & -do- & 223340 & $\begin{array}{l}\text { Karahiyanala, Sonebhadra, } \\
\text { UP }\end{array}$ & $4 x$ \\
\hline PV44 & -do- & 22334 & $\begin{array}{l}\text { Enroute Tippajharia } \\
\text { Sonebhadra, UP }\end{array}$ & $4 x$ \\
\hline PV45 & -do- & NA & $\begin{array}{l}\text { Enroute Tippajharia, } \\
\text { Sonebhadra, UP }\end{array}$ & $4 x$ \\
\hline PV46 & -do- & 223335 & Ballia nala, Sonebhadra, UP & $4 x$ \\
\hline
\end{tabular}

(Continued)
TABLE 1 | Continued

\begin{tabular}{|c|c|c|c|c|}
\hline $\begin{array}{l}\text { Sample } \\
\text { number }\end{array}$ & Taxon & $\begin{array}{l}\text { Voucher } \\
\text { number }\end{array}$ & Locale/Habitat & Cytotype \\
\hline PV47 & -do- & 229856 & FH, NBRI, Lucknow, UP & $5 x$ \\
\hline PV48 & -do- & & FH, NBRI, Lucknow, UP & $5 x$ \\
\hline $\mathrm{PC} 1$ & $\begin{array}{c}\text { Pteris } \\
\text { cretica L. } \\
\text { var. } \\
\text { albolineata }\end{array}$ & LP & FH, NBRI, UP Lucknow, UP & $2 x$ \\
\hline PC2 & -do- & LP & FH, NBRI, UP Lucknow & $2 x$ \\
\hline PC3 & -do- & LP & FH, NBRI, UP Lucknow & $2 x$ \\
\hline PC4 & $\begin{array}{l}\text { P. cretica L. } \\
\text { var. Cristata }\end{array}$ & LP & FH, NBRI, UP Lucknow & $2 x$ \\
\hline PE1 & $\begin{array}{l}\text { Pteris } \\
\text { ensiformis } \\
\text { Burm.f. }\end{array}$ & LP & Palayamkottai, Tirunelveli, TN & $3 x$ \\
\hline PE2 & -Do- & LP & FH, NBRI, UP Lucknow & $3 x$ \\
\hline PP1 & $\begin{array}{c}\text { Pteris } \\
\text { pellucida } \\
\text { Pr. }\end{array}$ & 223314 & Wayanad, KER & $2 x$ \\
\hline PQ1 & $\begin{array}{c}\text { Pteris } \\
\text { quadriaurita } \\
\text { Retz. }\end{array}$ & 223316 & Kodaikanal, TN & $4 x$ \\
\hline PT1 & $\begin{array}{c}\text { Pteris } \\
\text { tremula R. } \\
\mathrm{Br} .\end{array}$ & 223324 & Kodaikanal, TN & ND \\
\hline $\mathrm{MP}^{a}$ & $\begin{array}{l}\text { Microsorum } \\
\text { punctatum }\end{array}$ & LP & FH, NBRI, Lucknow, UP & $2 x$ \\
\hline
\end{tabular}

In all cases, leaf tissue was harvested, mopped free of dirt and stored over silica-gel in dry form in packets as described.

The sample number refers to the numbers assigned to the tissue samples.

MPa: Microsorum punctatum, used in the present study as an outgroup; NA: voucher number not available; ND: Ploidy not determined; LP: Live plants, FH, NBRI, Lucknow, UP; DNS: Did not survive.

Planting materials was collected at the referred locality and planted at the FH, NBRI, Lucknow, UP. However, plants died within a couple of months.

Location Abbreviations: AP - Arunachal Pradesh State; ASM - Assam State; FH, NBRI, Lucknow, UP - Fern House at National Botanical Research Institute (NBRI), Lucknow, Uttar Pradesh; KER - Kerala State; MAH - Maharashtra State; MEG Meghalaya State; MP - Madhya Pradesh State; TN - TamilNadu State; UKD Uttarakhand State; UP - Uttar Pradesh State; SKM - Sikkim State.

formula $\mathbf{H}_{n}=\mathbf{1}-\Sigma \mathbf{p}_{i}{ }^{2}$ where $\mathbf{p}_{i}$ is the allele/band frequency of the "ith" allele and " $n$ " is the total number of loci. The arithmetic mean heterozytgosity $\mathbf{H}_{a v}$ was calculated for each marker class using the formula $\mathbf{H}_{a v}=\Sigma \mathbf{H}_{n} / \mathbf{n}$ where $\mathbf{n}$ is the number of markers (loci) analysed. The fraction of polymorphic loci $\beta$ was calculated from the relationship $\beta=\mathbf{n}_{p} /\left(\mathbf{n}_{p}+\mathbf{n}_{n p}\right)$ where $\mathbf{n}_{p}$ and $\mathbf{n}_{n p}$ are the numbers of polymorphic and non-polymorphic loci analysed. The average heterozygosity for all markers equals to the average heterozygosity for polymorphic markers multiplied by the fraction of markers that are polymorphic, $\beta$. If $\mathbf{n}$ independent loci are analysed simultaneously and the average expected heterozygosity (probability that two different alleles are observed for each of loci, averaged over all loci considered) is $\mathbf{H}_{a v}$. Then for a pair of genotype being compared, the number of polymorphic marker per gel lane called marker index (MI), is determined from the relation $\mathbf{M I}=\mathbf{n} \mathbf{H}_{a v}$ or $\mathbf{M I}=\mathbf{n} \beta \mathbf{H}_{a v(p)}$ where $\beta \mathbf{H}_{a v(p)}$ is average or mean heterozygosity of polymorphic loci. The number of polymorphic loci in the germplasm set, 
TABLE 2 | List of primers used for all PCR based profiling methods.

\begin{tabular}{|c|c|c|}
\hline $\begin{array}{l}\text { SPAR method } \\
\text { (primer source) }\end{array}$ & Primer name & $\begin{array}{l}\text { Primer sequence from } 5^{\prime} \text { to } 3^{\prime} \\
\text { (length) }\end{array}$ \\
\hline \multirow[t]{25}{*}{ RAPD (QOP) } & OP-F07 & CCGATATCCC (10 mer) \\
\hline & OP-F08 & GGGATATCGG (10 mer) \\
\hline & OP-G07 & GAACCTGCGG (10 mer) \\
\hline & OP-G09 & CTGACGTCAC (10 mer) \\
\hline & OP-G12 & CAGCTCACGA (10 mer) \\
\hline & OP-G15 & ACTGGGACTC (10 mer) \\
\hline & OP-G17 & ACGACCGACA (10 mer) \\
\hline & OP-H02 & TCGGACGTGA (10 mer) \\
\hline & OP-HO3 & AGACGTCCAC (10 mer) \\
\hline & OP-H06 & ACGCATCGCA (10 mer) \\
\hline & $\mathrm{OP}-\mathrm{HO} 7$ & CTGCATCGTG (10 mer) \\
\hline & $\mathrm{OP}-\mathrm{HOO}$ & GAAACACCCC (10 mer) \\
\hline & OP-H11 & CTTCCGCAGT (10 mer) \\
\hline & OP-M05 & GGGAACGTGT (10 mer) \\
\hline & OP-M07 & CCGTGACTCA (10 mer) \\
\hline & OP-M11 & GTCCACTGTG (10 mer) \\
\hline & OP-U06 & ACCTTGCGG (10 mer) \\
\hline & OP-U08 & GGCGAAGGTT (10 mer) \\
\hline & OP-U11 & AGACCCAGAG (10 mer) \\
\hline & OP-U13 & GGCTGGTTCC (10 mer) \\
\hline & OP-U15 & ACGGGCCAGT (10 mer) \\
\hline & OP-W01 & CTGAGTGTCC (10 mer) \\
\hline & OP-W03 & GTCCGGAGTG (10 mer) \\
\hline & OP-ZO9 & CACCCCAGTC (10 mer) \\
\hline & OP-Z10 & CCGACAAACC (10 mer) \\
\hline \multirow[t]{4}{*}{ DAMD (BGE) } & HVR & ССТССТСССТССТ (13 mer) \\
\hline & HBV & GGTGTAGAGAGGGGT (15 mer) \\
\hline & 33.6 & GGAGGTGGGCA (11 mer) \\
\hline & M13 & GAGGGTGGCGGTTCT (15 mer) \\
\hline \multirow[t]{8}{*}{ ISSR (UBC) } & 825 & $(\mathrm{AC})_{8} \mathrm{~T}(17 \mathrm{mer})$ \\
\hline & 854 & $(\mathrm{TC})_{8} \mathrm{RG}$ (18 mer) \\
\hline & 855 & $(\mathrm{AC})_{8} \mathrm{YT}(18 \mathrm{mer})$ \\
\hline & 868 & $(\mathrm{GAA})_{6}(18 \mathrm{mer})$ \\
\hline & 873 & $(\mathrm{GACA})_{4}(16 \mathrm{mer})$ \\
\hline & 879 & $(\mathrm{CTTCA})_{3}(15$ mer $)$ \\
\hline & 888 & $\mathrm{BDB}(\mathrm{CA})_{7}(17$ mer) \\
\hline & 889 & $\mathrm{DBD}(\mathrm{AC})_{7}(17$ mer $)$ \\
\hline
\end{tabular}

Initially larger numbers of primers were screened.

From amongst these those giving clear, reproducible profiles with all template DNAs tested are detailed below.

Data from these primers was used for all further analyses.

$B=(C, G, T)$, i.e., not $A ; D=(A, G, T)$, i.e., not $C ; R=(A, G) ; Y=(C, T)$.

$B G E=$ Bangalore Genei, India; $Q O P=$ Qiagen Operon Company, United States; $U B C=$ University of British Columbia, Canada.

analysed per experiment, called effective multiplex ratio $\mathbf{E}$ is defined as: $\mathbf{E}=\mathbf{n} \beta$ and $\mathbf{M I}=\mathbf{E} \mathbf{H}_{a v(p)}$. The marker index, therefore, is simply the product of effective multiplex ratio and the average expected heterozygosity for the polymorphic markers. The band data for all the methods was also combined together for a cumulative analysis for the three methods in the same way as for individual methods. From the pair wise similarity data, the UPGMA phenogram was computed after allowing a 1000 replicate bootstrap test using the same programme. The phenogram was viewed, annotated and printed using Tree View (ver. 1.6.5; Page 2001). The AMOVA, Mantel correlations and PCA were computed using the programmes GenAlEx (ver. 6.5, Peakall and Smouse, 2006) while Shannon indices of diversity and geneflow were computed using POPGENE (ver. 1.32, Yeh et al., 1997) for the cumulative SPAR profile data by considering groups of tetraploid, pentaploid and other species of Pteris as discrete "populations."

\section{RESULTS}

A total of fifty seven (Table 1) Pteris genotypes which include PV1 to PV48 (all genotypes of $P$. vittata) and five other species (PC1 to PC4, PP1, PT1, PQ1, PE1, and PE 2) along with Microsorum punctatum as non-Pteris outgroup (Table 1) were selected for the diversity analysis. The chromosome numbers were determined as described and is listed in Table 1 corresponding to the sample studied. The SPAR analysis was carried out after a preliminary pilot study to test a number of primers as well as the PCR conditions in small sets before the entire set of accessions were studied (data not shown). The pilot study allowed us to optimise the various reaction parameters and assay conditions such that the profiles could be consistent and reproducible. From such profiles for the primers listed in Table 2, band data was scored individually for each primer in each method prior to analysis. Additionally for the cumulative analysis, the band data for all the primers in all the methods were combined into a single matrix prior to analysis. Typical PCR profiles obtained with one primer by each method are shown in Figure 2 as a representative. The UPGMA dendrograms for the band data by each method individually as well as by all three methods considered cumulatively are given in Figure 3 while the UPGMA dendrogram for the cumulative band data for the three methods is also depicted as a radial dendrogram as given in Figure 4. The PCA plot is given in Figure $\mathbf{5}$ for the data that considers groups of "tetraploid," "pentaploid," and "Other species" accessions as discrete "populations."

\section{ISSR Analysis}

DNA from 57 different varieties of Pteris, were amplified using the microsatellite primers (oligonucleotides from 15 to 18 nucleotides long, with a few degenerate nucleotides) as given in Table 2. The typical ISSR profiles obtained for 57 Pteris genotypes with UBC-825 are depicted in Figure 2A. Primer UBC-825 seemed to generate a single band in all accessions of $P$. vittata. A total of 127 bands in the size range of 2002400 bp were scored with the eight primers used. The bands obtained with all the primers were cumulatively considered for determining the Jaccard coefficient and the UPGMA dendrogram after a 1000 replicate bootstrap analysis of the data is shown in Figure 3A. The outgroup M. punctatum was clearly separated from the rest of the Pteris species. $P$. vittata is also well separated from other species but the group of accessions of $P$. vittata could be resolved into three prominent subclusters that included 27 (PV2, PV4, PV7, PV11-12, PV25-43), 19 (PV1, PV3, PV5-6, PV810, PV13-24), and two (PV47-48) accessions, respectively. The 


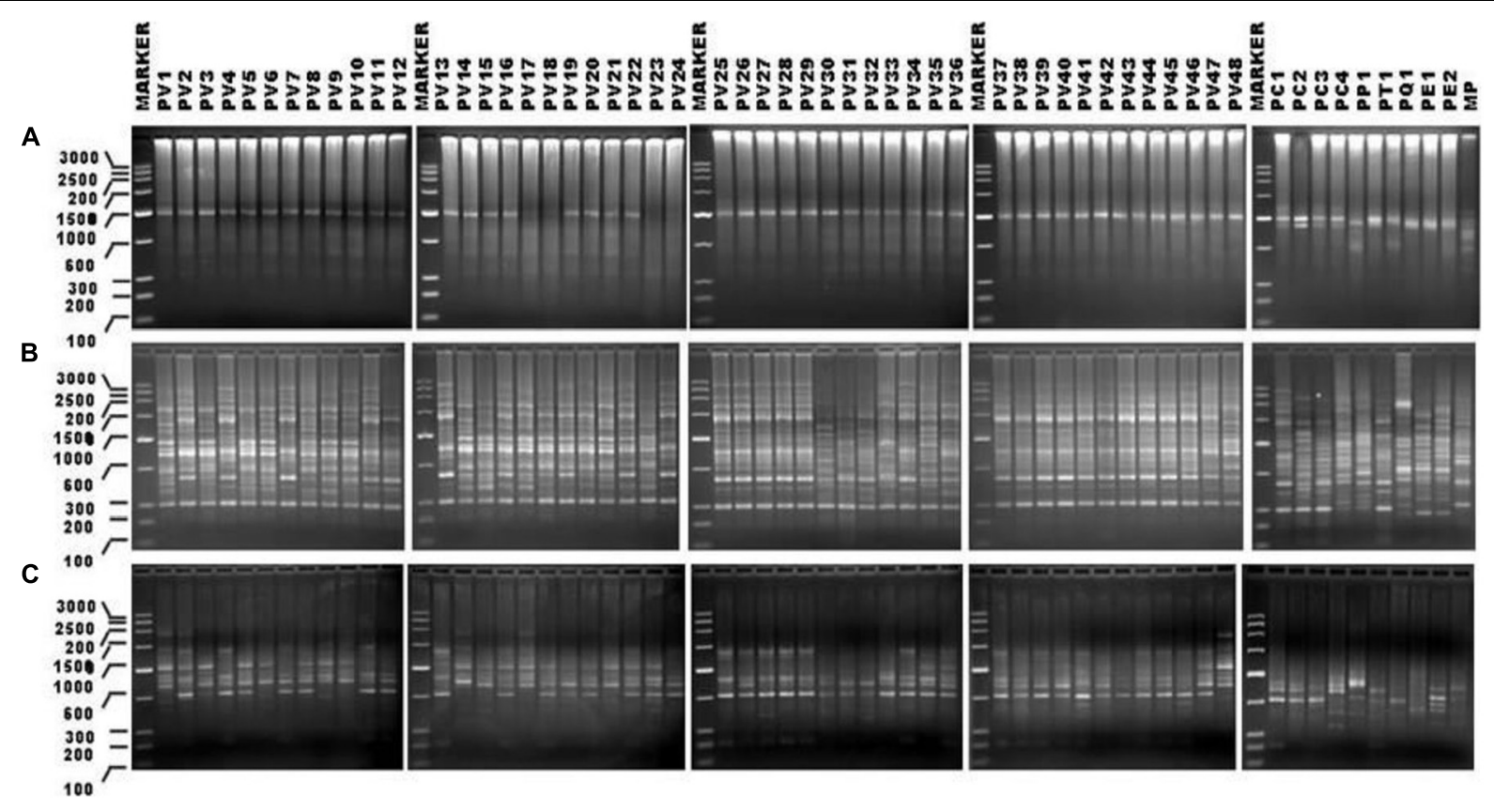

FIGURE 2 | SPAR profile obtained in case of 57 genotypes of Pteris DNAs with the ISSR primer UBC-825 (A); PAMD primer HVR (B), and RAPD primer OP-H02 (C). The Lines are marked with sample names as abbreviated in Table 1. The lanes where DMA molecular size marker (Low Range Rnlei) was loaded are marked as MARKER. Sizes of the marker fragments (in bp) are indicated on the scale to the left of the first gel image in all three panels. All agarose gels for the profiles are $1.2 \%$ $(w / v)$ in TBE 0.5X.

distribution of accessions in different sub-clusters in the UPGMA dendrogram was not congruent to their geographic provenance or their ploidy status.

\section{DAMD Analysis}

A distinctly polymorphic banding pattern was obtained with four minisatellite primers HVR(-), HBV, 33.6 and M13 after amplification of the Pteris genotypes and typical amplification profiles with the DAMD primers HVR are depicted in Figure 2B. Though no individual specific profile was obtained with the four DAMD primers, these exhibited a high extent of polymorphism across all the genotypes and a total of 194 bands were scored in the range of 200-3500 bp with the four DAMD primers. From the band data, Jaccard similarity coefficients and UPGMA dendrograms were computed as described for the ISSR method. The UPGMA tree after 1000 replicate bootstrapping is shown in Figure 3B. The dendrogram for the DAMD data could be resolved into five subclusters for the $P$. vittata accessions that included one (PV12), 24 (PV2, PV4, PV7, PV11, PV25-29, PV3246), 19 (PV1, PV3, PV5-6, PV8-10, PV13-24), two (PV47-48), and two (PV30-31) accessions, respectively.

\section{RAPD Analysis}

A total of 16 RAPD primers (Table 2) were used for analysis of the $P$. vittata accessions. Typical RAPD profiles obtained with the primers OP-H02 in these fifty seven genotypes of Pteris and one outgroup M. punctatum are shown in Figure 2C. Cumulatively, these primers have resulted in a total of 390 bands in size from 200 to $3500 \mathrm{bp}$. The UPGMA dendrogram was generated after a 1000-replicate bootstrap analysis and is shown in Figure 3C. In the dendrogram, the outgroup $M$. punctatum is separated from the rest of the Pteris accessions with $P$. vittata also being separated from the cluster of other Pteris species. All the P. vittata accessions are grouped into three sub-clusters such that the first subcluster included 24 (PV1-24) accessions, the second included 22 (PV25-46) accessions, and the third subcluster included two (PV47-48) accessions.

\section{Cumulative Analysis of the Data by All Three SPAR Methods}

In all three methods, the pentaploid genotypes PV47 and PV48 were always separated out from rest of the genotypes indicating that these were substantially different from the rest of $P$. vittata accessions. Each of the individual SPAR methods resulted in a robust assessment of the diversity since the outgroup taxa (both non-vittata as well as non-Pteris outgroups) always separated from the genotypes of $P$. vittata. In all three cases, the clusters were not specific to any group of genotypes in terms of ploidy status or geographical provenance of the genotypes (Figures 3A-C). In order to, therefore, have a comprehensive description of the relative affinities of the genotypes to each other, the band data for all primers in the three methods were considered cumulatively and the resultant UPGMA dendrogram is shown in Figures 3D, 4 where it is depicted in a radial form to better illustrate the numbers and nature of the subclusters. This UPGMA dendrogram, after 1000 replicate bootstrap of the data results in a much clearer picture about the relative affinities of the 

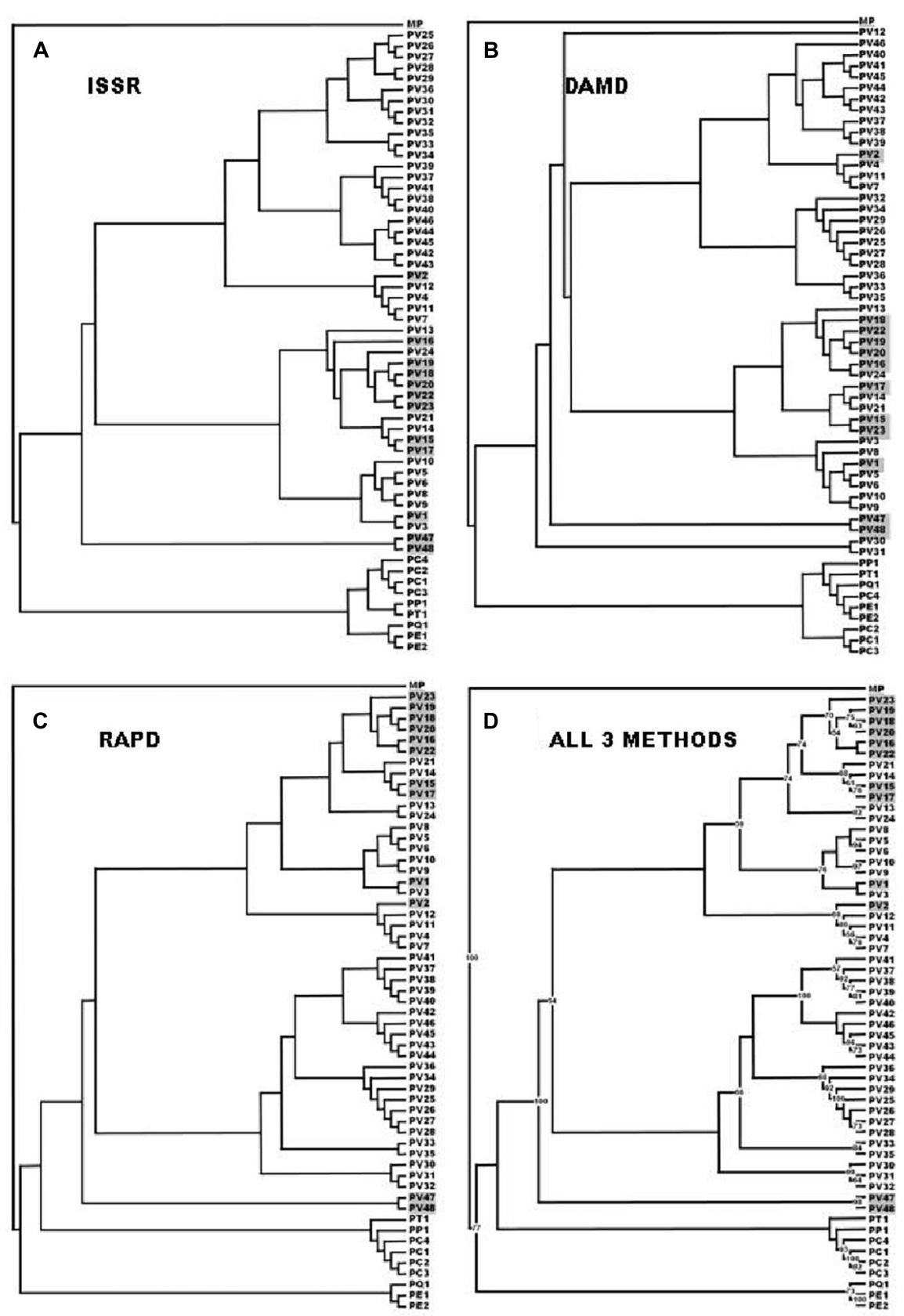

FIGURE 3 | The UPGMA dendrogram with 1000 replicate bootstrap analysis based on the Jaccard coefficient of similarity for all three SPAR methods (ISSR) were considered cumulatively. PV 1-PV 23: UP - Uttar Pradesh State except PV 3, that was from UKD - Uttarakhand State; PV 24 and PP 1: KER - Kerala State; PV 25-PV 26: MAH - Maharashtra State; PV 27- PV 29: TN - TamilNadu State; PV 30-PV 35: MEG - Meghalaya State; PV $36:$ SKM - Sikkim State; PV 37 and PV 39 PV 48: UP - Uttar Pradesh state; PV 38: MP - Madhya Pradesh State; PC 1-PC 4 and PE 2: UP - Uttar Pradesh State; PE 1: TN - TamilNadu State; PP 1: KER Kerala State; PQ 1 and PT 1: TN - TamilNadu State. MP: Microsorum punctatum, used in the present study as an outgroup.

genotypes to each other. The outgroup taxon M. punctatum is well separated from all the taxa. The group of taxa represented by $P$. ensiformis, $P$. quadriaurita, $P$. tremula, $P$. cretica, and P. pellucida is also well separated from all other Pteris genotypes. In the latter broad group, the $P$. vittata genotypes are included in three distinct subclusters well supported by a strong bootstrap values (Figure 3D). The radial tree illustrates these subclusters distinctly with the pentaploid accessions of $P$. vittata namely PV47 and PV48 again forming a distinct sub-cluster while the other two subclusters include 22 (PV25-46) and 24 (PV1-24) accessions, respectively. The cumulative dendrogram is most congruent to the RAPD data dendrogram than to DAMD and ISSR data dendrograms. The average similarities as well as the range of similarity values in case of each method as well as 


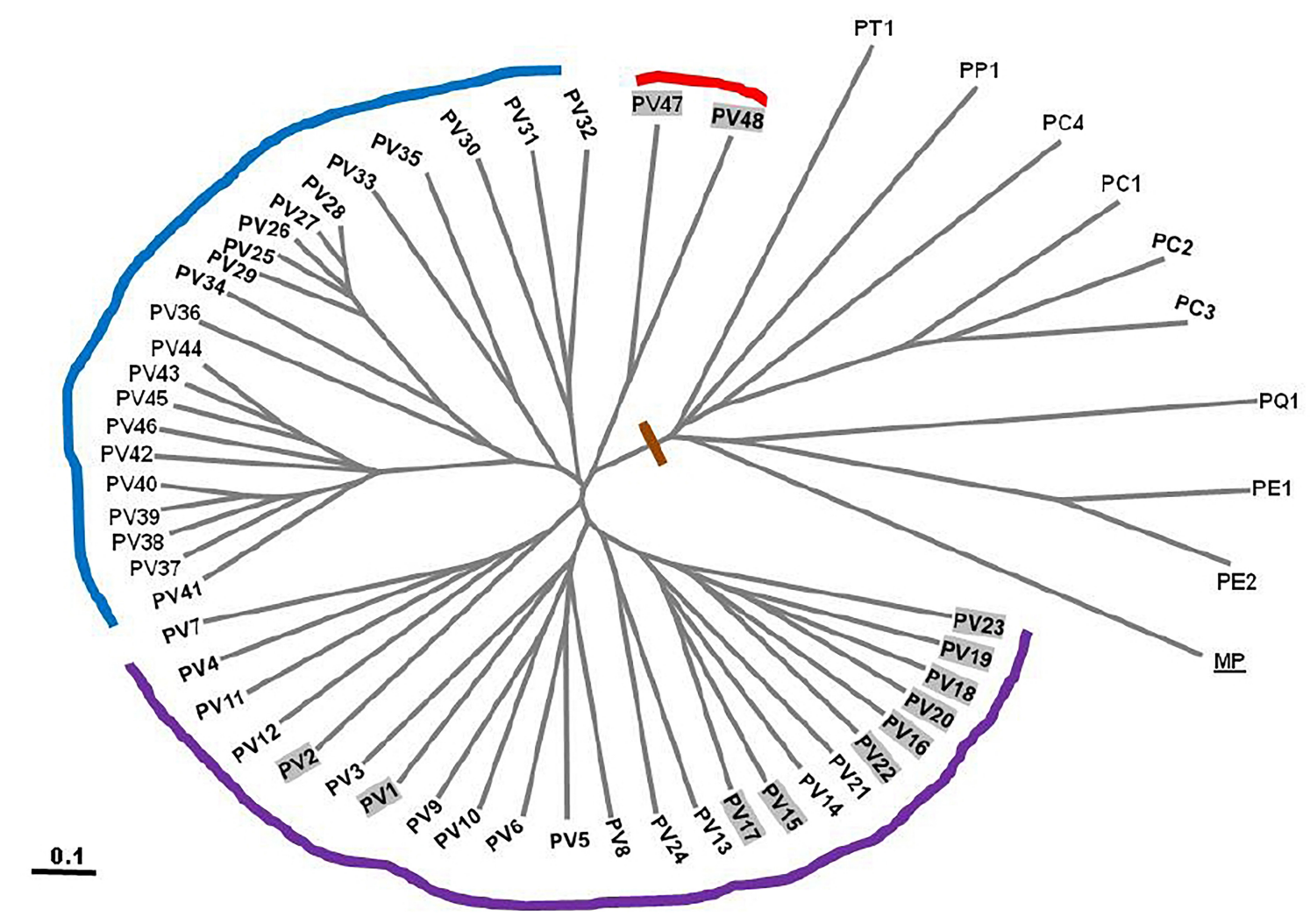

FIGURE 4 | UPGMA dendrogram of cumulative band data for 57 genotypes of Pteris depicted in a radial form after 1000 replicate bootstrap. PV1-PV 57 -57 genotypes of $P$. vittata from various locations of India (Table 1). PE: P. ensiformis, PQ: P. quadriaurita, PT: P. tremula, PC: P. cretica, PP: P. pellucida, MP: Microsorum punctatum (outgroup).

for all methods together are given in Table 3 which shows that the ISSR method detected the highest average similarities within the $P$. vittata genotypes while the RAPD and DAMD methods reveal almost similar averages. In general even when compared across other species of Pteris ISSR method always revealed the highest average similarities suggesting more similarities across the taxa in their SSR sequences. In order to determine the utility of each of the method used to assess the diversity in Pteris, at the intra- as well as inter-species levels, a comparative statistical assessment was done and MI, expected average heterozygosity, fraction of polymorphic loci and EMR were calculated in case of each of the methods used in the present study, as already described in the materials and methods. In case of ISSR-PCR within P. vittata accessions, the MI was 4.42, EMR was 12.3 and expected average heterozygosity was 0.36 . At the other species level, the corresponding values for MI, EMR and expected heterozygosity were 9.36, 23.41, and 0.40, respectively (Table 4). Similarly, DAMD had MI as 11.55 (within P. vittata) and 8.38 (within other species), EMR as 27.5 and 21.25 within $P$. vittata and other species, respectively. DAMD method resulted in the highest marker index value 11.55 for $P$. vittata group and ISSR for other species group having the MI value 9.36. These results confirm that DAMD method results in the highest marker index as well as the least probability of a random match. RAPD method, at the intra species level, showed values of MI 6.34 (within
P. vittata) and 4.67 (within other species), EMR 16.7 (within P. vittata) and 13.72 (within other species), expected average heterozygosity within $P$. vittata was 0.38 and within other species 0.34 . Though the individual methods had high MI and related statistics, overall, the cumulative analysis of more than one SPAR method data seems to be more efficient and robust in describing inter- as well as intra-species relationships.

The cumulative data for all three methods was resolved to indicate three groups or "populations," respectively, for the 36 tetraploid, 12 pentaploid, and nine species accessions for the analysis of parameters like AMOVA, PCoA, and the other "population" parameters (Table 5). The AMOVA values clearly indicated a more than $3.5 \mathrm{x}$ fold greater variation within the accessions in the three groups than among the groups themselves (Table 6). The computed Nei's original estimates for genetic distances among the populations are least between tetra- and pentaploids than between either of these with the other species (Table 7).

\section{DISCUSSION}

The use of molecular methods, especially PCR methods (SPAR methods) for the determination and analysis of genetic diversity in higher plants is very common and prolific over the past two 


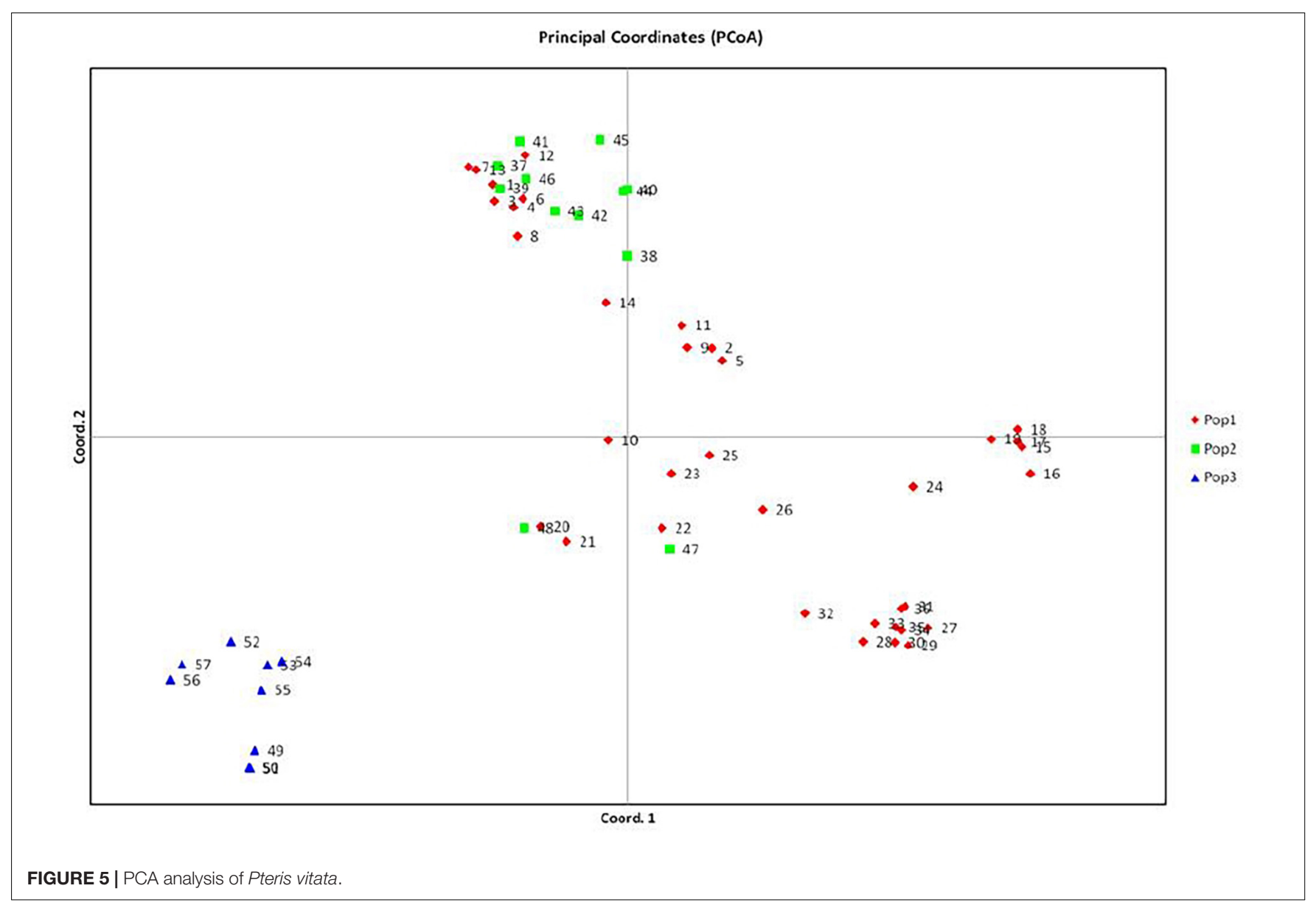

decades since the RAPD method was first described by Welsh and McClelland (1990) and Williams et al. (1990). However, the use of SPAR methods in case of pteridophytes is not as prolific as in the case of the higher plants. The RAPD analysis method was found to be highly informative in case of other ferns or fern allies such as Dryopteris remota (A. Braun) Druce (Schneller et al., 1998), two species of Botrychium Swartz, namely B. minganense Vict. and B. crenulatum Wagner (Swartz and Brunsfeld, 2002), and Archangiopteris itoi Shieh (Hsu et al., 2000). In case of Alsophila spinulosa, Wang et al. (2004) have studied

TABLE 3 | Comparison of the average similarity determined by three SPAR methods as well as primer-combination PCR, within P. vittata and other species in the species set.

\begin{tabular}{lcccc}
\hline Comparison & ISSR & DAMD & RAPD & Three SPAR methods \\
\hline Within Pteris vittata & & & & \\
Average & 0.54 & 0.65 & 0.61 & 0.44 \\
Range & $0.29-0.90$ & $0.29-0.96$ & $0.28-0.87$ & $0.18-0.75$ \\
Range Difference & 0.61 & 0.67 & 0.59 & 0.57 \\
Within Pteris species & & & & \\
Average & 0.17 & 0.14 & 0.90 & 0.11 \\
Range & $0.04-0.85$ & $0.0-0.94$ & $0.15-1.0$ & $0.01-0.084$ \\
Range Difference & 0.81 & 0.94 & 0.85 & 0.83
\end{tabular}

the population structure of this relict fern using RAPD and other PCR methods. We have earlier reported the use of SPAR methods for diversity analysis in case of P. vittata (Srivastava et al., 2008) and Equisetum species (Srivastava et al., 2009).

The occurrence of different cytotypes and possible subspecies in $P$. vittata suggests diversity of not only reproductive success

TABLE 4 | Comparison of efficiency of three SPAR methods for 57 genotypes of Pteris.

\begin{tabular}{llcc}
\hline Methods & Parameter & $\begin{array}{c}\text { P. vittata (48 } \\
\text { accessions) }\end{array}$ & $\begin{array}{c}\text { Other species } \\
\text { (9 accessions) }\end{array}$ \\
\hline \multirow{2}{*}{ ISSR } & Number of assay units & 8 & 8 \\
& Expected average heterozygosity & 0.36 & 0.40 \\
& Effective Multiplex Ratio & 12.3 & 23.41 \\
& Marker Index & 4.42 & 9.36 \\
DAMD & Number of assay units & 4 & 4 \\
& Expected average heterozygosity & 0.42 & 0.39 \\
& Effective Multiplex Ratio & 27.5 & 21.25 \\
\multirow{4}{*}{ RAPD } & Marker Index & 11.55 & 8.38 \\
& Number of assay units & 16 & 16 \\
& Expected average heterozygosity & 0.38 & 0.34 \\
& Effective Multiplex Ratio & 16.7 & 13.72 \\
& Marker Index & 6.34 & 4.67
\end{tabular}


in the P. vittata but also of the genetic diversity extant amongst the different genotypes. The molecular assessment of genetic diversity using SPAR methods can be determined easily and with these considerations, inter- as well as intra-species analysis was carried out in with 57 accessions of $P$. vittata as well as of other species of Pteris with M. punctatum considered as an out group taxon. The three SPAR methods individually as well as collectively did not distinguish the two polyploid cytotypes of $P$. vittata from each other. The SPAR profiles have revealed mostly polymorphic bands and no two profiles were identical. In the individual methods, the range of similarity coefficients amongst the $P$. vittata accessions was $0.61,0.67$, and 0.59 , respectively, for ISSR, DAMD, and RAPD methods (Table 3). The corresponding values for accessions of different species of Pteris used in the study are $0.81,0.94$, and 0.83 , respectively, for the three methods. In both cases the DAMD method seemed to resolve the wider range indicating that this method may a better resolution of the polymorphism in the profiles. This is clearly supported by the computation of marker index (Table 4) that was the highest among all three methods in case of accessions of $P$. vittata while in case of the accessions of the other species Pteris the ISSR and DAMD had relatively higher values of MI though the MI for ISSR was higher than that for DAMD. Clearly, for intraspecies comparison, the DAMD was superior to all other methods while for the inter-species comparison, ISSR method was more

TABLE 5 | Analysis of "population" similarity coefficients for the cumulative band data for all accessions considered as groups of tetraploid, pentaploid, and other species accessions.

\begin{tabular}{lcccc}
\hline Group & Range SI & Average SI & No. of pairs & Total SI \\
\hline Pop1 (4x) & $0.166-0.918$ & 0.363 & 630 & 228.728 \\
Pop2 (5x) & $0.185-0.691$ & 0.406 & 66 & 26.813 \\
Pop3 (Spp) & $0.083-0.696$ & 0.182 & 36 & 6.500 \\
Pop1-Pop2 & $0.182-0.579$ & 0.323 & 432 & 139.561 \\
Pop1-Pop3 & $0.054-0.186$ & 0.107 & 324 & 34.699 \\
Pop2-Pop3 & $0.05-0.154$ & 0.104 & 108 & 11.236 \\
\hline
\end{tabular}

TABLE 6 | AMOVA analysis of cumulative band data for all accessions considered as groups of tetraploid, pentaploid, and other species accessions.

\begin{tabular}{lccccc}
\hline Source of variation & Df & SS & MS & Est. Var. & $\%$ \\
\hline Among three groups & 2 & 641.110 & 320.555 & 17.114 & $22 \%$ \\
Within the three groups & 54 & 3301.417 & 61.137 & 61.137 & $78 \%$ \\
Total & 56 & 3942.526 & & 78.252 & $100 \%$ \\
\hline
\end{tabular}

TABLE 7 | Nei's Original measure of genetic distance (above diagonal) calculated according to [see Nei (1973) Am. Nat. 106:283-292] and Unbiased Measures of genetic distance (below diagonal) calculated according to [see Nei (1978) Genetics 89:583-590].

\begin{tabular}{lccc}
\hline Accession group & $\begin{array}{c}\text { Tetraploid } \\
\boldsymbol{P} \text { vittata }\end{array}$ & $\begin{array}{c}\text { Pentaploid } \\
\boldsymbol{P} \text {. vittata }\end{array}$ & Other species \\
\hline Tetraploid P. vittata & $\star \star \star \star *$ & 0.0180 & 0.0497 \\
Pentaploid P. vittata & 0.0140 & $\star \star \star \star$ & 0.0653 \\
Other Species & 0.0448 & 0.0584 & $* \star \star \star$
\end{tabular}

informative. In case of mulberry Bhattacharya et al. (2005) have observed that DAMD had the higher MI than ISSR and RAPD in a set that included exotic and indigenous accessions of mulberry. On the other hand, in case of accessions of betelvine (Piper betle L.), when these were compared using SPAR methods to distinguish between genders, the ISSR method was found to have the higher MI (Ranade et al., 2011). The marker index is a measure of the ability of the method to resolve the greatest polymorphism and the fact that DAMD method has such a resolving power is also borne out by the observations made in case of papaya (Saxena et al., 2005), mango (Srivastava et al., 2007). This resolving power of the method may be due to the possibility that the minisatellite sequences in a genome are more frequently subjected to inversions due to which the SPAR profile can be obtained with the minisatellite primers in DAMD method. These profiles are actually of regions between successive minisatellite regions and thus represent length polymorphism for these regions across a set of accessions compared.

The cumulative band data was resolved to reflect three groups as discrete "populations" and included all tetraploid accessions in one group, all pentaploid accessions in another and accessions of different species in the third group. In this case the tetraploid accessions showed the highest range of similarities for all three methods cumulatively while the least range was in case of the pentaploid accessions. Thus the pentaploid accessions differed from each other in a narrower range than the tetraploid accessions. The greater range of similarity values in the tetraploid accessions indicates a greater diversity amongst these accessions and this is supported by estimates of mean Shanon's Informative index as well as mean estimate of Nei's gene diversity (Table 8). The schema for generation of higher polyploid cytotypes of P. vittata (Khare and Kaur, 1983a) involves hybridisation between diploids, triploids, and tetraploids. According to this the pentaploid cytotypes are thought to have derived from some of the tetraploid. Since the hybridisation is suggested as the dominant route for polyploidisation the different genomes involved are not necessarily multiple copies of each other. If this is true we will not obtain any high similarities between and amongst the different polyploidy accessions of $P$. vittata. However, considering that the schema for pentaploid accessions to be formed invokes only a common hybridisation approach it is possible that the mechanisms for generating the different pentaploid accessions used in the present study are more similar than they are different. Hence more pentaploids are similar to each other to a greater extent than the tetraploids are similar to each other. The UPGMA dendrogram based on the Jaccard coefficient of similarity showed that the accessions were clustered into four major clades with no specific correlation between ploidy types or geographical origin. The accessions of different species of Pteris formed a separate clade (Figures 3, 4). The dendrogram was robust in separating out the non-Pteris outgroup taxon, M. punctatum. The UPGMA dendrogram reveals that $48 P$. vittata accessions are resolved into three subclusters (Figure 4) and does not show any ploidy specific distribution of the genotypes. These results are consistent with the complexity of the species. However, since no correlation was obtained with the polyploidy types and their relative affinities to 
each other, it is not possible to state with any certainty that the greater diversity in $P$. vittata genotypes is due to the polyploid cytotypes that they include. In other pteridophytes like Adiantum pedatum L., incipient polyploidisation has also been reported (Rabe and Haufler, 1992) and this mechanism could operate in P. vittata too.

For the present study $48 \mathrm{P}$. vittata (36 tetraploid and 12 pentaploid) and five of other species (four $P$. cretica, one $P$. pellucida, one $P$. tremula, one $P$. quadriaurita, and two $P$. ensiformis) accessions were used. The UPGMA dendrograms were generated for each method separately (Figures 3A-C), respectively, as well as for all methods cumulatively (Figures 3D, 4), after a 1000 replicate bootstrap analysis. In each case the outgroup taxon, M. punctatum was well separated from the Pteris species clusters. Further in each method as well as collectively by all methods, the three different species of Pteris always separated. The dendrogram clearly shows that the $P$. vittata accessions were resolved into three subclusters suggesting that many possible genetic lineages since the sub-clusters were not based on any geographical or polyploidy status of the accessions.

The increased number of genotypes particularly in case of $P$. vittata resulted in assessment of a wide range of average similarities for each method individually as well as for the cumulative data (Table 4). A similar trend was observed even for within Pteris species comparison. This is an important observation. In order that the best estimate of diversity is determined, it is essential that an adequately large number of genotypes are sampled. This is further illustrated from comparison of different methods. Thus we observed that marker index determined by RAPD, DAMD, and ISSR methods increased from 5.1 to $6.34,11.31$ to 11.55 , and 3.51 to 4.22 , respectively, in case of larger number of genotypes relative to smaller number of genotypes used (Table 4). At the level of individual methods highest MI was obtained for DAMD method. This suggest that DAMD analysis can differentiate more genotypes per assay in $P$. vittata, however, when other species are also considered in the same analysis we found ISSR to have the highest MI (Table 4).
The parameters of MI or EMR have been assessed in a large number of plants as well as for two or more PCR methods used in the same set of genotypes. However, the values determined for a given set of methods and for a given set of genotypes, reveal a relatively better or the best method for the comparative studies. In case of pteridophytes, however, no such calculations have ever been made to our knowledge.

In higher plants there are several reports of more than one SPAR method used for determining the genetic diversity. The different SPAR methods generate genome-wide profiles in the sense that the profiles originate from several discrete regions spread through the genome. However, the nature of amplifiable sequences in each method differs considerably. For example, RAPD profiles originate from randomly distributed sequences to which the primers can anneal; the ISSR profiles originate from regions rich in microsatellite sequences while the DAMD profiles are due to the minisatellite-rich regions of the genomes. In a few cases any or all of these regions could overlap due to interspersion of sequence types or classes. Hence the genotype affinities to each other may not always be the same by all methods. Under these circumstances a cumulative analysis of the data generated in each method may enable the most comprehensive assessment of the genomic affinities of the genotypes used in the study. Recently two studies in case of horticultural crops papaya and mango have shown that a combined analysis using two or more SPAR methods also enable the correlation with genotypes studied; as was found in case of papaya for pulp colour and incase of mango for pedigree on parentage of the genotypes (Saxena et al., 2005; Srivastava et al., 2007). The separate analysis of data generated by each method, however, allows the determination of parameters such as MI and average heterozygosity that in turn qualify a given method as the most useful or informative method for a given set of genotypes or for a given set of the taxa.

These analyses in the present study also have enabled conclusion about the most useful methods for diversity analysis in the fern P. vittata L. Interestingly, such a study is unique in case of the ferns to our knowledge. DAMD method in most cases

TABLE 8 | Analysis of "population" parameters for the cumulative band data for all accessions considered as groups of tetraploid, pentaploid, and other species accessions.

\begin{tabular}{|c|c|c|c|c|c|c|c|c|c|}
\hline $\begin{array}{l}\text { Accession group } \\
\text { (No. of samples) }\end{array}$ & $\begin{array}{l}\text { Polymorphic } \\
\text { loci (\%) }\end{array}$ & $\begin{array}{l}\text { Mean na* } \\
\text { (SD) }\end{array}$ & $\begin{array}{l}\text { Mean ne* } \\
\text { (SD) }\end{array}$ & $\begin{array}{l}\text { Mean } h^{*} \\
\text { (SD) }\end{array}$ & $\begin{array}{l}\text { Mean I* } \\
\text { (SD) }\end{array}$ & $\begin{array}{l}\text { Mean Ht } \\
\text { (SD) }\end{array}$ & $\begin{array}{l}\text { Mean Hs } \\
\text { (SD) }\end{array}$ & Mean Gst & Mean Nm* \\
\hline $\begin{array}{l}\text { Tetraploid P. vittata } \\
\text { (36) }\end{array}$ & 58.51 & $\begin{array}{l}1.585 \\
(0.49)\end{array}$ & $\begin{array}{l}1.195 \\
(0.28)\end{array}$ & $\begin{array}{l}0.126 \\
(0.16)\end{array}$ & $\begin{array}{l}0.205 \\
(0.23)\end{array}$ & NA & NA & NA & NA \\
\hline $\begin{array}{l}\text { Pentaploid P. vittata } \\
\text { (12) }\end{array}$ & 47.96 & $\begin{array}{l}1.480 \\
(0.50)\end{array}$ & $\begin{array}{l}1.192 \\
(0.30)\end{array}$ & $\begin{array}{c}0.1210 \\
(0.16)\end{array}$ & $\begin{array}{l}0.193 \\
(0.24)\end{array}$ & NA & NA & NA & NA \\
\hline Other Species (9) & 56.82 & $\begin{array}{l}1.568 \\
(0.50)\end{array}$ & $\begin{array}{l}1.166 \\
(0.23)\end{array}$ & $\begin{array}{l}0.117 \\
(0.13)\end{array}$ & $\begin{array}{l}0.198 \\
(0.21)\end{array}$ & NA & NA & NA & NA \\
\hline All $P$. vittata (48) & 64.42 & $\begin{array}{l}1.644 \\
(0.48)\end{array}$ & $\begin{array}{l}1.199 \\
(0.28)\end{array}$ & $\begin{array}{l}0.131 \\
(0.16)\end{array}$ & $\begin{array}{l}0.214 \\
(0.23)\end{array}$ & $\begin{array}{l}0.132 \\
(0.03)\end{array}$ & $\begin{array}{l}0.124 \\
(0.02)\end{array}$ & 0.060 & 7.891 \\
\hline $\begin{array}{l}\text { All accessions used } \\
\text { (57) }\end{array}$ & 92.41 & $\begin{array}{l}1.924 \\
(0.27)\end{array}$ & $\begin{array}{l}1.205 \\
(0.25)\end{array}$ & $\begin{array}{l}0.140 \\
(0.14)\end{array}$ & $\begin{array}{l}0.239 \\
(0.20)\end{array}$ & $\begin{array}{l}0.147 \\
(0.02)\end{array}$ & $\begin{array}{l}0.127 \\
(0.01)\end{array}$ & 0.14 & 3.150 \\
\hline
\end{tabular}

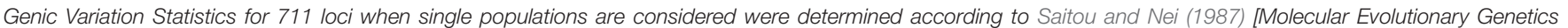


$I^{*}=$ Shannon's Information index according to Lewontin (1972).

$\mathrm{Nm}^{*}=$ estimate of gene flow from Gst as Nm = 0.5(1-Gst)/Gst according to McDermott and McDonald (1993).

Nei's Analysis of Gene Diversity in Subdivided Populations were computed basically according to Saitou and Nei (1987). 
resulted in the highest MI values indicating that the minisatellite sequences may have a greater role in genome diversification.

\section{DATA AVAILABILITY STATEMENT}

The original contributions presented in the study are included in the article/supplementary material, further inquiries can be directed to the corresponding author.

\section{DEDICATION}

This manuscript is dedicated to the memory of S. A. Ranade (posthumously) who enormously contributed in the field of plant genetic diversity and molecular taxonomy also supervised the present work.

\section{REFERENCES}

Aulakh, M. K., Kaur, N., and Saggoo, M. I. S. (2019). Bioactive phytoconstituents of pteridophytes-a review. Indian Fern. J. 36, 37-79.

Belaj, A., Satovic, Z., Cipriani, G., Baldoni, L., Testolin, R., Rallo, L., et al. (2003). Comparative study of the discriminating capacity of RAPD, AFLP and SSR markers and their effectiveness in establishing genetic relationships in olive. Theor. Appl. Genet. 107, 736-744. doi: 10.1007/s00122-003-1301-5

Bhattacharya, E., Dandin, S. B., and Ranade, S. A. (2005). Single primer amplification reaction methods reveal exotic and indigenous mulberry varieties are similarly diverse. J. Biosci. 30, 669-675. doi: 10.1007/bf02703567

Bir, S. S., and Irudayaraj, V. (2001). Cytology of some ferns from the Nilgiris, South India IV. Fern. Gazette 16, 177-190.

Chao, Y.-S., Liu, H.-Y., Chiang, Y.-C., and Chiou, W.-L. (2012). Polyploidy and speciation in Pteris (Pteridaceae). J. Bot. 2012, 817920. doi: 10.1155/2012/ 817920

Fjellheim, S., Elven, R., and Broachmann, C. (2001). Molecules and morphology in concert. II. The Festuca brachyphylla complex (Poaceae) in Svalbard. Amer. J. Bot. 88, 869-882. doi: 10.2307/2657039

Gupta, M., Chyi, Y. S., Romero-Severson, J., and Owen, J. L. (1994). Amplification of DNA markers from evolutionarily diverse genomes using single primers of SSRs. Theor. Appl. Genet. 89, 998-1006. doi: 10.1007/bf00224530

Hassler, M., and Swale, B. (2001). Checklist of World Ferns. Available online at: http://homepages.caverock.net.nz/ \{\}bj/fern/list.htm (accessed November 16, 2018).

Hsu, T.-W., Moore, S.-J., and Chiang, T.-Y. (2000). Low RAPD polymorphism in Archangiopteris itoi, a rare and endemic fern in Taiwan. Bot. Bull. Acad. Sin. 41, 15-18. doi: 10.2307/1545239

Jaccard, P. (1908). Etude comparative dela distribution florale dans une portion des Alpes et des Jura. Bull. Soc. Vaudoise Sci. Nat. 37, 547-579.

Khare, P. B. (1995). Studies in Pteris vittata L. complex. Indian Fern. J. 12, 43-50.

Khare, P. B., and Kaur, S. (1983a). Intraspecific polyploidy in Pteris vittata L. Cytologia 48, 21-25. doi: 10.1508/cytologia.48.21

Khare, P. B., and Kaur, S. (1992). Variable gametophytic differentiation in triploid Pteris vittata Linn. Proc. Nat. Acad. Sci. India 62B, 557-559.

Kimura, M. and Crow, J. F. (1964). The number of alleles that can be maintained in a finite population. Genetics. 49:725.

Kuo, L. Y., Ebihara, A., Hsu, T. C., Rouhan, G., Huang, Y. M., Wang, C. N., et al. (2018). Infrageneric revision of the fern genus Deparia (Athyriaceae, Aspleniineae, Polypodiales). Syst. Bot. 43, 645-655. doi: 10.1600/ $036364418 \times 697364$

Lavanya, G. R., Srivastava, J., and Ranade, S. A. (2008). Molecular assessment of genetic diversity in Mungbean germplasm. J. Genet. 87, 65-74.

Leitch, I. J., and Bennett, M. D. (2004). Genome downsizing in polyploid plants. Bio. J. Lin. Soc. 82, 651-663. doi: 10.1111/j.1095-8312.2004.00349.x

Mahar, K. S., Rana, T. S., Ranade, S. A., and Meena Baleshwar. (2011). Genetic variability and population structure in Sapindus emarginatus Vahl from India. Gene 485, 32-39. doi: 10.1016/j.gene.2011.05.036

\section{AUTHOR CONTRIBUTIONS}

JM executed the experiments of this research work under the supervision of PK. All authors contributed to the article and approved the submitted version.

\section{ACKNOWLEDGMENTS}

We are grateful to Aditya Shastri (Vice Chancellor), Banasthali Vidyapith, Rajasthan for his support and encouragement. We also acknowledge the St. Xavier's College at Tirunelveli (Tamil Nadu), Botanical Survey of India at Coimbatore (Tamil Nadu), Kolkata (West Bengal), and Itanagar (Arunachal Pradesh), and Department of Botany, Calicut University, Calicut, Kerala, for help with plant material.

Mahar, K. S., Rana, T. S., Ranade, S. A., Pande, V., and Palni, L. M. S. (2012). Estimation of genetic variability and population structure in Sapindus trifoliatus L.,using DNA Fingerprinting Methods. Trees - Structure and Function. 27, 85-96. doi: 10.1007/s00468-012-0770-z

Manton, J. (1950). Problems of Cytology and Evolution in Pteridophytes. London: Cambridge University Press.

McDermott J. M. and McDonald, B. A. (1993) Gene Flow in Plant Pathosystems. Ann. Rev. Phytopathol. 31: 353-373.

Narzary, D., Rana, T. S., and Ranade, S. A. (2010). Molecular analyses of genetic diversity in indian pomegranates using RAPD, DAMD and ISSR. Food Veg. Cereal Sci. Biotech. 4, 126-143.

Nei, M. (1973). Analysis of gene diversity in subdivided populations. Proc. Natl. Acad. Sci U.S.A. 70, 3321-3323. doi: 10.1073/pnas.70.12.3321

Nei, M. (1978). Estimation of average heterozygosity and genetic distance from a small number of individuals. Genetics. 89, 583-590.

Otto, S. P. and Sauquet, H. (2018). Macroevolutionary patterns of flowering plant speciation and extinction. Annu. Rev. Plant Biol. 69, 9-1. doi: 10.1146/annurevarplant-042817-040348

Pavlicek, A., Hrda, S., and Flegr, J. (1999). FreeTree - Freeware program for construction of phylogenetic trees on the basis of distance data and bootstrapping / jackknife analysis of the tree robustness. Application in the RAPD analysis of the genus Frenkelia. Folia Biol. 45, 97-99.

Peakall, R., and Smouse, P. E. (2006). GenAlEx 6: genetic analysis in Excel. Population genetic software for teaching and research. Mol. Ecol. Notes 6, 288-295. doi: 10.1111/j.1471-8286.2005.01155.x

Peirson, J. A., Dick, C. W., and Reznicek, A. A. (2013). Phylogeography and polyploid evolution of North American goldenrods (Solidago subsect. Humiles, Asteraceae). J. Biogeogr. 40, 1887-1898. doi: 10.1111/jbi.12136

Powell, W., Morgante, M., Andre, C., Hanafey, M., Tingey, S., and Rafalski, A. (1996). The comparison of RFLP, RAPD, AFLP and SSR (microsatellite) markers for germplasm analysis. Mol. Breed. 2, 225-238. doi: 10.1007/ bf00564200

Rabe, E. W., and Haufler, C. H. (1992). Incipient polyploid speciation in the maidenhair fern (Adiantum pedatum. Adiantaceae). Amer. J. Bot. 79, 701-707. doi: 10.1002/j.1537-2197.1992.tb14611.x

Ramsey, J., and Schemske, D. W. (1998). Pathways, mechanisms and rates of polyploidy formation in flowering plants. Ann. Rev. Ecol. Syst. 29, 467-501. doi: 10.1146/annurev.ecolsys.29.1.467

Ranade, S. A., Rana, T. S., and Narzary, D. (2009). SPAR profiles and genetic diversity amongst pomegranate (Punica granatum L.) genotypes. Physiol. Mol. Biol. Plants 15, 61-70. doi: 10.1007/s12298-009-0006-x

Ranade, S. A., Soni, A., and Kumar, N. (2011). "SPAR profiles for the assessment of genetic diversity between male and female landraces of the dioecious betelvine plant (Piper betle L.)," in Biodiversity - Book 1, ed. O. Grillo (Croatia: Intech Open Access Publishers), 443-464.

Ranade, S. A., Srivastava, A. P., Rana, T. S., Srivastava, J., and Tuli, R. (2008). Easy assessment of diversity in Jatropha curcas L. plants using two Single Primer 
Amplification Reaction (SPAR) methods. Biomass Bioenergy 32, 533-540. doi: 10.1016/j.biombioe.2007.11.006

Rogstad, S. H. (1993). Surveying Plant Genomes for variable numbers of tendem repeat loci. Meth. Enzymol. 224, 278-294. doi: 10.1016/0076-6879(93)24021-1

Saitou, N. and Nei, M. (1987). The neighbor-joining method: a new method for reconstructing phylogenetic trees. Mol. Biol. Evol. 4, 406-425. doi: 10.1093/ oxfordjournals.molbev.a040454

Sambrook, J., Fritsch, E. F., and Maniatis, T. (1989). Molecular Cloning : A Laboratory Manual, 2nd Edn. New York, NY: Cold Spring Harbor Laboratory.

Saxena, S., Chandra, R., Srivastava, A. P., Mishra, M., Pathak, R. K., and Ranade, S. A. (2005). Analysis of genetic diversity among papaya cultivars using Single Primer Amplification Reaction (SPAR) methods. J. Horticult. Sci. Biotechnol. 80, 291-296. doi: 10.1080/14620316.2005.11511932

Schneller, J., Holderegger, R., Gugerli, F., Eichenberger, K., and Lutz, E. (1998). Patterns of genetic variation detected by RAPDs suggest a single origin with subsequent mutations and long-distance dispersal in the apomictic fern Dryopteris remota (Dryopteridaceae). Am. J. Bot. 85, 1038-1042. doi: 10.2307/ 2446372

Schuettpelz, E., Grusz, A. L., Windham, M. D., and Pryer, K. M. (2008). The utility of nuclear gapCp in resolving polyploid fern origins. Syst. Bot. 33, 621-629. doi: 10.1600/036364408786500127

Schuettpelz, E., Schneider, H., Huiet, L., Windham, M. L., and Pryer, K. M. (2007). A molecular phylogeny of the fern family Pteridaceae: assessing overall relationships and the affinities of previously unsampled genera. Mol. Phylogenet. Evol. 44, 1172-1185. doi: 10.1016/j.ympev.2007.04.011

Soltis, D. E., Soltis, P. S., and Tate, J. A. (2004). Advances in the study of polyploidy since Plant speciation. N. Phytol. 161, 173-191. doi: 10.1046/j.1469-8137.2003. 00948.x

Soltis, P. S., and Soltis, D. E. (2000). The role of genetic and genomic attributes in the success of polyploids. Proc. Natl. Acad. Sci. U.S.A. 97, 7051-7057. doi: 10.1073/pnas.97.13.7051

Srivastava, A. P., Chandra, R., Saxena, S., Rajan, S., Ranade, S. A., and Prasad, V. (2007). A PCR-based assessment of genetic diversity, and parentage analysis among commercial mango cultivars and hybrids. J. Horticult. Sci. Biotechnol. 82, 951-959. doi: 10.1080/14620316.2007.11512332

Srivastava, J., Ranade, S. A., and Khare, P. B. (2007). Distribution and threat status of the cytotypes of Pteris vittata L. (Pteridaceae) species in India. Curr. Sci. 93, 81-85.

Srivastava, J., Ranade, S. A., and Khare, P. B. (2009). "SPAR profiling analysis supports two subgenera for the genus Equisetum L," in Plant and Fungal Biodiversity and Bioprospecting, eds S. Krishnan and D. J. Bhat (Panjim: Broadway Publishers), 87-98.

Srivastava, J., Ranade, S. A., Srivastava, R., and Khare, P. B. (2008). "RAPD profile diversity amongst two polyploid accessions of Pteris vittata L," in Perspectives in Pteridophytes, eds S. C. Verma, S. P. Khullar, and H. K. Cheema (Dehradun: BSMPS Publishers), 433-443.

Swartz, L. M., and Brunsfeld, S. J. (2002). The morphological and genetic distinctness of Botrychium minganense and B. crenulatum as assessed by morphometric analysis and RAPD markers. Am. Fern J. 92, 249-269. doi: 10.1640/0002-8444(2002)092[0249:tmagdo]2.0.co;2

Verma, S., Rana, T. S., and Ranade, S. A. (2009). Genetic variations and clustering in Murraya paniculata complex, revealed by single primer amplification reaction (SPAR) methods. Curr. Sci. 96, 1210-1216.

Wang, T., Su, J.-Y., Li, X.-Y., Zheng, B., Chen, G.-P., and Zeng, Q.L. (2004). Genetic structure and variation in the relict populations of Alsophila spinulosa from southern China based on RAPD markers and cpDNA atpB-rbcL sequence data. Hereditas 140, 8-17. doi: 10.1111/j.1601-5223.2004.01659.x

Welsh, J., and McClelland, M. (1990). Fingerprinting genomes using PCR with arbitrary primers. Nucl. Acids Res. 18, 7213-7218. doi: 10.1093/nar/18.24.7213

Williams, J. G. K., Kubelik, A. R., Livak, K. J., Rafalski, J. A., and Tingey, S. V. (1990). DNA polymorphisms amplified by arbitrary primers are useful as genetic markers. Nucl. Acids Res. 18, 6231-6235.

Yang, B., Hu, M., Zhou, M., Guan, J. P., Zhang, J., Lan, C. Y., et al. (2010). Development of eight polymorphic microsatellite markers by FIASCO-based strategy for a arsenic-hyperaccumulator Chinese brake fern. Conservation Genet Resour 2, 65-67. doi: 10.1007/s12686-009-9169-6

Yeh, F. C., Yang, R.-C., and Boyle, T. (1997). POPGENE - A Microsoft Windowsbased freeware for population genetic analysis, ver. 1.31 (32 bit). Available online at: http://www.ualberta.ca/ fcyeh/

Zhou, Z., Bebeli, P. J., Somers, D. J., and Gustafson, J. P. (1997). Direct amplification of minisatellite- region DNA with VNTR core sequences in the genus Oryza. Theor. Appl. Genet. 95, 942-949. doi: 10.1007/s00122005 0645

Conflict of Interest: The authors declare that the research was conducted in the absence of any commercial or financial relationships that could be construed as a potential conflict of interest.

The reviewer DA declared a shared affiliation with one of the authors PK to the handling editor at the time of review.

Publisher's Note: All claims expressed in this article are solely those of the authors and do not necessarily represent those of their affiliated organizations, or those of the publisher, the editors and the reviewers. Any product that may be evaluated in this article, or claim that may be made by its manufacturer, is not guaranteed or endorsed by the publisher.

Copyright (c) 2021 Mathur, Khare, Panwar and Ranade. This is an open-access article distributed under the terms of the Creative Commons Attribution License (CC BY). The use, distribution or reproduction in other forums is permitted, provided the original author(s) and the copyright owner(s) are credited and that the original publication in this journal is cited, in accordance with accepted academic practice. No use, distribution or reproduction is permitted which does not comply with these terms. 